\title{
Importância da conduta do cirurgião-dentista frente à contenção e prevenção do Covid-19
}

\author{
Amanda Gonçalves Franco' \\ José Cláudio Faria Amorim ${ }^{1}$ \\ Geraldo Alberto Pinheiro de Carvalho ${ }^{2}$ \\ Sergio Candido Dias $^{2}$ \\ Aline Batista Gonçalves Franco 2
}

"Pandemia" é o termo usado pelos pesquisadores da área da saúde para caracterizar o cenário que estamos vivendo atualmente. As pandemias podem ser definidas como epidemias de doenças de caráter infeccioso que se espalham por vários países durante um mesmo período de tempo. Em dezembro de 2019, um surto de pneumonia começou na China e se espalhou por várias regiões geográficas, sendo causado pelo vírus que chamamos de Coronavírus, ou como muitos chamam, Covid -19.desse grupo de vírus, podendo lançar o vírus do tipo SARSCoV que pertence a mesma família do SARS-CoV-2. No entanto, atualmente, ainda não se sabe a real origem e os possíveis vetores intermediários da SARS-CoV-2, bem como o mecanismo exato. Benvenuto et al. [9] destaca que através de uma análise filogenética foi possível encontrar uma origem de morcego para o SARS-CoV-2. Ele ainda menciona que este vírus está relacionado apenas ao coronavírus específico do tipo SARS de morcego isolado de Rhinolophus sinicus em 2015 na China.

Os dados acerca do vírus relatam que o mesmo apresenta uma elevada capacidade de infecção. Diante disso, sabe-se que as principais vias de transmissão incluem a transmissão direta, através de tosse e espirros; a transmissão por contato com superfícies contaminadas pelo vírus; e a transmissão indireta, por meio de fluidos e saliva.

Levando em conta as características de um que incluem uma proximidade face a face entre os cirurgiõesdentistas e pacientes, exposição a saliva e outros fluidos, possibilidade de contato com sangue, além de instrumentos manuais, cortantes ou não, que podem estar contaminados, faz-se necessário um cuidado redobrado em relação ao manejo do paciente, limpeza do consultório e proteção do profissional e auxiliares de consultório diante do Covid-19. Ademais, sabe-se que, durante um atendimento, há possibilidade de ocorrer dispersão de respingos e aerossóis contendo patógenos provenientes da seringa tríplice e turbina de alta rotação utilizados nos atendimentos clínicos. Portanto, existe a possibilidade de ocorrer uma contaminação cruzada. Vêse assim a necessidade de colocação de barreiras físicas entre os equipamentos, assim como uma proteção de toda a face, o corpo, o cabelo e os braços do operador, sendo estas regiões bastante atingidas pelos respingos. Contudo, apesar de suspenderem os atendimentos odontológicos em muitas regiões, o atendimento de urgência ainda está presente. E essas medidas se tornam essenciais a fim de que tornem os profissionais e pacientes protegidos da transmissão do vírus.

O consultório odontológico deve ser cuidadosa e primorosamente limpo antes de se iniciar os atendimentos. Deve ser realizada uma desinfecção rigorosa nos materiais, equipamentos do consultório odontológico e também nas maçanetas, cadeiras e no banheiro. Para isso sugere-se

\footnotetext{
${ }^{1}$ Universidade de Itaúna, Faculdade de Odontologia. Itaúna, MG, Brasil.

2 Faculdade São Leopoldo MaWndic, Curso de Odontologia. Rua José Rocha Junqueira, 13, Swift, 13045-755, Campinas, SP, Brasil Correspondência para / Correspondence to: AG FRANCO. E-mail: <aalinebgfranco@yahoo.com>.
} 
Hipoclorito de Sódio a 0,1\%, Peróxido de Hidrogênio a 0,5\%, álcool a 70\%, ou até mesmo um desinfetante a ser padronizado pelo serviço de saúde para essa finalidade, de forma que todas superfícies tocadas sejam desinfetadas. Isso é essencial, visto que há relatos de sobrevivência do novo Coronavírus por 2 a 9 dias em superfícies. É importante também que se retire todas as revistas das salas de esperas a fim de evitar essa transmissão por contato direto ao tocar objetos contaminados e depois levar as mãos no nariz, boca ou nos olhos. A inativação do vírus pode ser alcançada após 1 minuto com uso de hipoclorito de sódio (principal componente da água sanitária). Portanto recomenda-se a utilização dos desinfetantes domésticos contendo hipoclorito de sódio. Usar preferencialmente a água sanitária 2-2,5\% - diluir uma parte de água sanitária $(250 \mathrm{ml}$ ) para 3 partes de água $(750 \mathrm{ml})$, para obter 1 litro a 0,5\% para desinfetar superfícies como pisos, azulejos e paredes. Se a superfície estiver suja deve ser limpa primeiramente com água e sabão ou detergente e após ser realizada a desinfecção.

Em relação ao tratamento odontológico, primeiramente, é necessário que o cirurgião-dentista lave criteriosamente as mãos com água e sabão por 20 a 30 segundos, antes e depois de todos os procedimentos. A fricção com o álcool $70 \%$ em gel se não estiver com sujidade visível por no mínimo 20 segundos, também é uma opção para o cirurgião dentista, quanto uma recomendação para o paciente. Essa necessidade se dá em vista de que a contaminação das mãos pelo vírus e a sua posterior inoculação nas mucosas oral, nasal e ocular é considerada uma das principais vias de transmissão. Vale lembrar que o cirurgião-dentista precisa retirar todos os adereços, como anéis, relógios e pulseiras antes de fazer essa lavagem. Após lavar as mãos deve-se secá-las com papel toalha.

Posteriormente, para o atendimento, todos os materiais de proteção individuais (EPI's) devem ser utilizados pelo cirurgião-dentista, tais como o gorro, o jaleco, a máscara, as luvas (que juntamente com a máscara devem ser trocadas antes de um novo procedimento) e os óculos de proteção. Viseiras ou protetores de face poderão ser usados para proporcionar uma proteção mais efetiva, porém nunca sem o uso da máscara. Além disso, depois de cada procedimento deve ser feita a desinfecção dos protetores de face e as máscaras devem ser retiradas por meio de suas tiras ou elásticos e não devem ser tocadas pelo profissional durante o atendimento. Vale ressaltar que no caso do uso de um jaleco não descartável, ele deve ser lavado separado das roupas do dia a dia, para não as contaminar.

Tuñas et al. (2020) considera a importância do dentista solicitar ao paciente que se faça um bochecho com Peróxido de Hidrogênio a $1 \%$ ou Lodopovidona a $0,2 \%$, já que a solução de Clorexidina a 0,12\%, bastante utilizado em Odontologia, não se faz eficaz na prevenção da transmissão do Covid-19. É necessário também, a realização do isolamento absoluto do campo operatório sempre que possível, visto ser uma ação que minimiza a geração de aerossóis com grande contaminação se utilizar alta rotação ou o ultrassom. Portanto, no caso da impossibilidade do isolamento, é viável bastante cautela durante o procedimento.

Recomenda-se também o uso de sugadores de alta potência, de maneira que o trabalho a quatro mãos seja estimulado para o controle de disseminação do vírus; assim como evitar a utilização da seringa tríplice na sua forma spray, acionando os dois botões ao mesmo tempo para regular a saída de água de refrigeração. Os motores com válvulas de antirretração ou antirrefluxo são altamente aconselhados para previnir contaminação cruzada. Apesar de já ser considerada uma das várias e principais medidas de biossegurança nos consultórios odontológicos, reforça-se a necessidade de realizar autoclavagem das peças de mão após todos os atendimentos, assim como todo o material deverá ser esterilizado em autoclaves. É preciso ressaltar também o cuidado no manuseio de materiais perfurocortantes, já que as infecções podem acontecer após acidentes com os mesmos.

Por fim, é muito importante a presença de álcool em gel $70 \%$ nas salas de espera, para uso do paciente, acompanhante e secretária. O cirurgião dentista como profissional da área da saúde, deve orientar o paciente em relação a higiene das mãos, etiqueta respiratória e de tosse, além de pedir para que evite o toque de mãos nos olhos, nariz ou boca, evitando dessa forma a contaminação.

Conclui-se, portanto, que são muitas as responsabilidades dos cirurgiões dentistas frente a essas novas medidas a serem tomadas. Essas medidas passam por uma boa orientação e um correto manejo do paciente; uma exímia limpeza do consultório; uma impecável esterilização do instrumental odontológico; uso de todos os equipamentos de proteção individual; assim como uma postura exemplar ao ser fiel a todos os tópicos citados anteriormente. No entanto, são medidas bastante necessárias e essenciais por se tratarem de condutas para conter e prevenir a contaminação pelo 
Covid-19 quanto mais aderirmos a essas medidas, mais rapidamente passaremos por essa Pandemia.

\section{REFERÊNCIAS}

1. Conselho Federal de Odontologia. Recomendações para atendimentos odontológicos em tempos de COVID-19. 2020. Disponível em: http://website. cfo.org.br/plano-de-prevencao-cfo-anuncia-novasmedidas-paraauxiliar-na-contencao-do-coronavirus/

2. Brasil. Ministério da Saúde. Agência Nacional de Vigilância Sanitária. Serviços Odontológicos: Prevenção e Controle de Riscos / Ministério da Saúde, Agência Nacional de Vigilância Sanitária. Brasília: Ministério da Saúde, 2006. Disponível em: http://www.anvisa. gov.br/servicosaude/manuais/manual_odonto.pdf

3. American Dental Association (ADA). What Constitutes a Dental Emergency? 2020. Disponível em: https:// success.ada.org/ /media/CPS/Files/Open\%20Files/ ADA_COVID19_Dental_Emergency_DDS.pdf?utm_ source=adaorg\&utm_medium=covid-resources $\mid p \& u t m \_$ content=cv-pm-emergdef\&utm_campaign $=$ covid $19 \&_{\text {_ }}$ $\mathrm{ga}=2.158719422 .527261862 .1584796909-$ $\begin{array}{llllllllllllllllllll}1 & 9 & 8 & 2 & 1 & 0 & 6 & 6 & 6 & 3 & 1 & 5 & 8 & 4 & 5 & 6 & 3 & 1 & 8 & 4\end{array}$

4. Center for Disease Control and Prevention (CDC). Interim Infection Prevention an Control for Patients with Suspected or Confirmed Coronavirus disease 2019 (COVID-19) in Healthcare Settings. Disponível em: https://www.cdc.gov/coronavirus/2019-ncov/ infection-control/controlrecommendations.html

5. Sociedade Brasileira de Infectologia. Informe $n^{\circ} 9$ da Sociedade Brasileira de Infectologia sobre o novo Coronavírus: perguntas e respostas para profissionais da saúdeeparao públicoemgeral(Atualizadoem20/03/2020).

6. World Health Association. Rational use of personal protective equipment for coronavirus disease (COVID-19)"; Considerations for quarantine of individuals in the context of containment for coronavirus disease (COVID-19). Disponível em: https://www.who.int/emergencies/ diseases/novel-coronavirus-2019/events-as-theyhappen

7. Zhang $W$, Jiang $X$. Measures and suggestions for the prevention and control of the novel coronavirus in dental institutions. Front Oral Maxillofac Med. 2020;2:4.
8. Ruiyun Li, Sen Pei, Bin Chen, Yimeng Song, Tao Zhang, Wan Yang, et al. Substantial undocumented infection facilitates the rapid dissemination of novel coronavirus (SARS-CoV2). Science. eabb3221.

9. Tuñas ITC, Silva ET, Santiago SBS, Maia KD, Silva-Júnior GO.I. Doença pelo Coronavírus 2019 (COVID-19): Uma abordagem preventiva para Odontologia. Revista Brasileira de Odontologia. 2020;77:e1766. Disponível em: http://revista.aborj. org.br/index.php/rbo/article/viewFile/1776/pdf 